\title{
Synthese
}

\section{Broadening the Scope of Our Understanding of Mechanisms: Lessons from the History of the Morning-After Pill \\ --Manuscript Draft--}

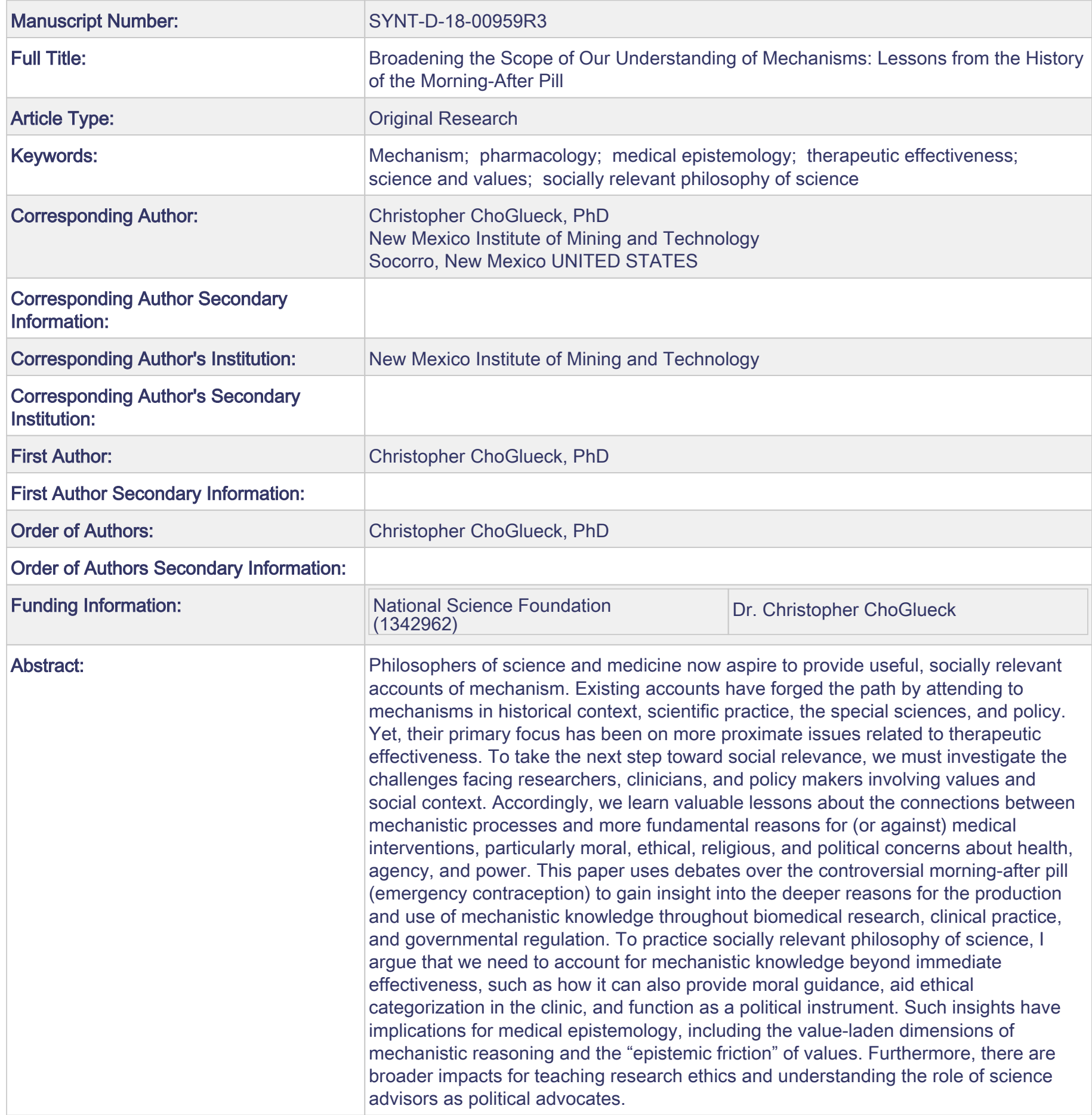


Author: Christopher ChoGlueck

Title: Broadening the Scope of Our Understanding of Mechanisms: Lessons from the History of the Morning-After Pill

Author affiliation: New Mexico Institute of Mining and Technology

Department of Communication, Liberal Arts, and Social Sciences

103 Fitch Hall

801 Leroy Place

Socorro, NM 87801

Email: cchoglueck@gmail.com

ORCID: 0000-0002-6095-2105

Acknowledgements: I gave an earlier version of this paper at the 2017 International Society for History, Philosophy and Social Studies of Biology in Sao Paulo, Brazil, and received many helpful comments from the audience. Special thanks to Elisabeth Lloyd and Jutta Schickore for advice and support. Additional thanks to Robyn Bluhm, Sandy Gliboff, Kate Grauvogel, Nora Hangel, Bennett Holman, Ashley Graham Kennedy, Naomi Oreskes, Emanuele Ratti, David Teira, and two anonymous reviewers for helpful comments and engaging conversations.

Funding: This material is based upon work supported by the National Science Foundation Graduate Research Fellowship Program under grant no. 1342962. Any opinions, findings, and conclusions or recommendations expressed in this material are those of the author and do not necessarily reflect the views of the National Science Foundation.

Conflict of interest: The author declares that he has no conflict of interest.

Abstract: Philosophers of science and medicine now aspire to provide useful, socially relevant accounts of mechanism. Existing accounts have forged the path by attending to mechanisms in historical context, scientific practice, the special sciences, and policy. Yet, their primary focus has been on more proximate issues related to therapeutic effectiveness. To take the next step toward social relevance, we must investigate the challenges facing researchers, clinicians, and policy makers involving values and social context. Accordingly, we learn valuable lessons about the connections between mechanistic processes and more fundamental reasons for (or against) medical interventions, particularly moral, ethical, religious, and political concerns about health, agency, and power. This paper uses debates over the controversial morning-after pill (emergency contraception) to gain insight into the deeper reasons for the production and use of mechanistic knowledge throughout biomedical research, clinical practice, and governmental regulation. To practice socially relevant philosophy of science, I argue that we need to account for mechanistic knowledge beyond immediate effectiveness, such as how it can also provide moral guidance, aid ethical categorization in the clinic, and function as a political instrument. Such insights have implications for medical epistemology, including the value-laden dimensions of mechanistic reasoning and the "epistemic friction" of values. Furthermore, there are broader impacts for teaching research ethics and understanding the role of science advisors as political advocates.

Keywords: mechanism, pharmacology, medical epistemology, therapeutic effectiveness, science and values, socially relevant philosophy of science 


\title{
Broadening the Scope of Our Understanding of Mechanisms: \\ Lessons from the History of the Morning-After Pill
}

\begin{abstract}
Philosophers of science and medicine now aspire to provide useful, socially relevant accounts of mechanism. Existing accounts have forged the path by attending to mechanisms in historical context, scientific practice, the special sciences, and policy. Yet, their primary focus has been on more proximate issues related to therapeutic effectiveness. To take the next step toward social relevance, we must investigate the challenges facing researchers, clinicians, and policy makers involving values and social context. Accordingly, we learn valuable lessons about the connections between mechanistic processes and more fundamental reasons for (or against) medical interventions, particularly moral, ethical, religious, and political concerns about health, agency, and power. This paper uses debates over the controversial morning-after pill (emergency contraception) to gain insight into the deeper reasons for the production and use of mechanistic knowledge throughout biomedical research, clinical practice, and governmental regulation. To practice socially relevant philosophy of science, I argue that we need to account for mechanistic knowledge beyond immediate effectiveness, such as how it can also provide moral guidance, aid ethical categorization in the clinic, and function as a political instrument. Such insights have implications for medical epistemology, including the value-laden dimensions of mechanistic reasoning and the "epistemic friction" of values. Furthermore, there are broader impacts for teaching research ethics and understanding the role of science advisors as political advocates.
\end{abstract}

\section{Introduction}

Thinking about mechanisms — that is, how something works, acts, or causes an effect—pervades scientific reasoning and policy making. Accordingly, philosophers of science have sought to 
provide accounts of mechanism that are useful for both researchers and policy makers. For instance, Carl Craver and Lindley Darden (2013, p. xviii) intend to "write a practically useful book for those engaged in discovery" by offering to contemporary researchers a framework of mechanism and strategies from the history of science. More geared toward policy makers, Federica Russo and Jon Williamson offer an alternative account of mechanisms to critique the evidence hierarchies that guide public-health policy, such as measuring environmental exposure and reducing obesity (Russo 2012; Russo and Williamson 2012). For an even broader audience, Nancy Cartwright and Jeremy Hardie (2012, p. 5) provide a guidebook for Evidence-Based Policy involving mechanistic reasoning, intended to be accessible to experts and laypeople involved in policy making including "classroom teachers thinking about homework, city councils deciding whether to build a leisure center, or government ministers contemplating drug policies." Clearly, these philosophers of science and medicine hope to provide practical and applicable accounts of mechanism.

Existing accounts have forged the path to scientific and social relevance. They have looked at mechanistic reasoning in its historical context and in practice (e.g., Machamer et al. 2000; Darden 2006; Craver \& Darden 2013), and they have expanded to include various special sciences and public policy (e.g., Illari \& Williamson 2012; Russo 2012; Clarke et al. 2014). ${ }^{1}$ First and foremost, philosophers of mechanism have sought to elucidate the reasoning by which scientists employ to connect a phenomenon with its causes, organization, processes, and parts

\footnotetext{
${ }^{1}$ I thank an anonymous reviewer for suggesting that socially relevant philosophy is the next step in the philosophy of mechanisms after the turns to history, practice, and the special sciences.
} 
(for reviews, see Craver and Tabery 2017; Glennan 2016; Illari and Williamson 2012). ${ }^{2}$ In biomedicine and health policy, they have shown in a variety of ways how mechanistic knowledge and reasoning involves the effectiveness of a treatment (i.e., its ability to produce an effect). They have found three possible roles for mechanisms in medicine that map onto the contexts of discovery, justification, and application, which I call the heuristic, evidential, and instrumental functions. ${ }^{3}$ First, the search for mechanisms of effective treatments has guided the methodology of how such knowledge is sought heuristically (Darden 2006; Craver and Darden 2013; Solomon 2015). Once found, mechanisms help clinicians to evidence claims about effectiveness epistemically (Russo and Williamson 2011; Howick 2011). Then, in policy making and society more generally, mechanistic reasoning provides an instrumental aid for making

${ }^{2}$ Overlooking some of the differences between their accounts, the specifics range from organized entities and activities that operate regularly and cyclically (Machamer et al. 2000) and complex systems whose parts interact directly and invariantly to make a difference between variables (Glennan 2002) to a structure performing a function by virtue of its organized parts (Bechtel and Abrahamsen 2005). However, for my purpose of understanding the production and use of mechanistic knowledge, these nuanced distinctions are immaterial.

${ }^{3}$ There has been extensive philosophical debate over the sharpness of these context-based distinctions and their epistemic import (see Schickore and Steinle 2006). Nevertheless, if understood as loosely overlapping phases operating throughout inquiry, they provide a useful structure for framing my analysis. 
effective interventions and applications (Cartwright and Hardie 2012; Russo 2012). ${ }^{4}$

Now, if we want to practice socially relevant philosophy of science, we must attend to the issues that are important to researchers, clinicians, and policy makers, particularly those involving human values and social context (Fehr and Plaisance 2010; Weaver 2017). While these philosophical accounts of mechanism have provided insightful analyses into more proximate issues related to therapeutic effectiveness, the time has come to explore the deeper challenges facing researchers, clinicians, and policy makers. These issues involve value questions about morality, ethics, and religion and the politics associated with the production and use of knowledge about mechanisms. Philosophers have argued forcefully for the importance of accounting for how context and values shape scientific research and science policy (Douglas 2009; Elliott 2011; Kitcher 2011; Longino 1990). For instance, the questions scientists ask-and the projects that get funded - are limited to those which they take to be significant, requiring value judgments about priority, framing, and use into the production of knowledge. Furthermore, managing different empirical uncertainties such as underdetermination and inductive risk also requires value judgments, often relying on contextual values with societal stakes (ChoGlueck 2018). To achieve social relevance, philosophers of mechanism should take this next step to broaden their accounts by including the interplay between science, medicine, and society.

Using an in-depth case study of the mechanism of the morning-after pill (emergency contraception), this paper argues that, antecedent to producing effective treatments, mechanistic knowledge relates to broader beliefs about health, agency, and power involving human values.

\footnotetext{
${ }^{4}$ Since I aim to expand and then reframe the discussion, I will not evaluate these existing arguments, although I will note criticisms (see footnotes 5, 7, 8, and 9).
} 
Here, researchers and policy makers produce and use mechanistic knowledge to determine what forms of effectiveness and what treatments are desirable in the first place. For one, we shall see how during initial development mechanistic knowledge can provide researchers with moral guidance regarding how to follow religious and ethical codes and to achieve political goals. Second, mechanistic reasoning can also help physicians in clinics categorize treatments over ethically loaded terrain. Third, it can equip researchers and healthcare professionals with the useful sort of scientific information needed for political advocacy. Rather than a simple epistemic means to effective intervention - the focus of existing philosophical accountsknowing and understanding mechanisms is a crucial aspect of many ethical, political, and social controversies. Accordingly, this paper argues that the time is ripe for philosophers to expand and reframe the discussion of mechanisms in medicine to attend to these humanistic and cultural aspects of mechanistic reasoning.

While this paper's immediate aim is descriptive, ultimately it enables a more critical project: understanding how mechanistic knowledge is used in biomedicine and health policy in order to improve it. For one, my analysis showcases value-laden dimensions of mechanistic reasoning and how they vary across context. In particular, we see how values create "epistemic friction." Values in early research and development shape the expertise and knowledge available (and absent). Values in clinics and hospitals promote the development of new classificatory schemes for novel, contentious treatments. The values of public advocacy groups prompt scientists to produce and promulgate specific forms of information for patients, governmental agencies, and courts.

Moreover, controversies over the mechanisms of contraceptives have enormous societal significance. The World Health Organization lists these "emergency contraceptives"- taken 
after sexual intercourse to reduce the chance of unwanted pregnancy — as a core essential medicine (WHO 2017, p. 40, 18.3.1). Virtually all women in the US have used contraception at one point in their lives (Daniels, Mosher, et al. 2013), and over last decade, 11\% (5.8 million) of US women of reproductive age had used emergency contraception specifically (Daniels, Jones, et al. 2013). One key obstacle to women's access to this important drug, as we shall see, has been concerns about its mechanism related to ethical and religious objections to abortion, particularly from Roman Catholics, entangling medical epistemology with reproductive ethics and gender politics.

An integrated methodology in history and philosophy of science (HPS) grounds this paper's aim at socially engaged philosophy. To articulate the challenges that researchers, doctors, and science advisors faced when producing and using knowledge about this mechanism, my analysis moves iteratively from the more abstract discussion of philosophers to the concrete details of history and back again (for a similar approach, see H. Chang 2011). As an HPS project, this paper seeks to provide lessons for philosophers about different aspects of mechanistic knowledge by working through three episodes in the history of the morning-after pill. Rather than merely reporting a case study based on historians' secondary accounts and then generalizing from it, I have conducted historical research from primary and secondary sources, which I use to make my own historical account and then engage critically with the relevant philosophical literature. I have utilized new primary sources, such as commentaries from Catholic physicians' journals and related Catholic hospital directives, Planned Parenthood conference proceedings, and peer-reviewed articles on emergency contraception. I have also drawn upon a wide variety of secondary sources, including Heather Prescott's ground-breaking (2011) monograph on the history of the morning-after pill, Lisa Wynn and Angel Foster's (2012) collected volume on the 
International Consortium for Emergency Contraception, Patricia Miller’s (2015) history of debates over abortion among American Catholics, and Daniel Williams's (2016) pre-history of the Pro-Life Movement. Nevertheless, unlike these other histories involving emergency contraception, particularly Prescott's (2011), my narrative highlights the long-standing concern with the pill's mechanism from both women's health advocates and anti-abortionists throughout the past fifty years. In particular, I trace the shifting functions afforded to mechanistic knowledge by people with different values and in different contexts. For geographical comparison, my account moves throughout North and South America, where most of the research was conducted and where several of the most contentious political battles took place.

Each section discusses the way philosophers have construed mechanistic knowledge or reasoning, followed by my own narrative and analysis of a different or broader function. This HPS iteration between history and philosophy takes us through several milestones in the saga of the morning-after pill, including its initial development, its subsequent clinical use, and its later governmental regulation. The chronology begins in the 1960s, during the spread of the first hormonal contraceptives, when research on the alternative "day-after" pills began in the US. Section 2 delves into how reasoning about post-coital mechanisms during this early development engaged researchers morally, either toward or against intervention—particularly Catholic doctors in the face of prohibitions on contraception and abortion from the Vatican. The next milestone is the spread of the first morning-after pill to clinics and hospitals throughout the world in the late 1960s and early '70s (before the discovery of the health risks of estrogen). Section 3 contrasts the different schemes employed by clinicians and hospital administrators for categorizing the new (off label) treatment as a contraceptive or abortifacient. The final milestone is the governmental regulation of safer progestin-based emergency contraceptives in the late 1990s and 
early 2000s, including legislative battles and court cases over women's access to this drug. Section 4 covers two of these recent struggles in the US and Chile, where scientists used mechanistic information as a political instrument either for women's agency in healthcare or for provider's rights to refuse offering these pills.

Reflecting on these insights, Section 5 argues that mechanistic knowledge is produced and used not only for understanding or utilizing effectiveness but more generally for promoting health; this broader understanding involves human life, norms, and values. There, I discuss how these lessons apply more broadly to other cases of mechanistic knowledge because of the relations of treatment mechanisms to cultural norms, ethical values, and economic currency. Section 6 discusses the implications of expanding beyond our current understanding of mechanisms for philosophy and society, spanning from the relations between values and mechanistic knowledge to the teaching of research ethics and the role of science advisers.

\section{Moral Guidance for/against Intervention after Coitus}

We begin with the search for mechanisms during early research and development. In the socalled context of discovery, philosophers have shown how mechanistic reasoning is significant for its heuristic function (Craver and Darden 2013; Darden 2006; Solomon 2015). Typically, drugs and other treatments must be researched and developed before they can be tested in human trials, evaluated by governments, and prescribed by physicians. Often this search in the field of "translational medicine" is framed around pathological and physiological mechanisms, which guide researchers by structuring their discovery toward fruitful outputs (Solomon 2015). Rather than thinking of discovery as a boundless endeavor without rules, Darden (2006) argues that 
mechanisms provide a logic of discovery. Therefore, if the goal is to discover mechanisms, there are many advisable strategies based on the history of science (see also Thagard 2011). She discusses these strategies at length, such as for the construction of hypotheses, evaluation of their plausibility, and revision according to new developments. For Darden, and others like Craver and Miriam Solomon, the significance of mechanisms during early research is first as the epistemic goal of inquiry and second as a heuristic that provides the means for achieving that goal (Craver and Darden 2013; Solomon 2015; see also La Caze 2011). ${ }^{5}$

In this section, I contend that mechanistic reasoning provides more than a heuristic for discovery by affording moral guidance over when and whether to intervene. To intervene, or not to intervene, that was the question- - but it was a moral question for individual researchers to discern. For the morning-after pill, thinking about the mechanism did guide initial development as well as later refinements toward more safe and effective formulations (e.g., Glasier et al. 1992; Morris, Van Wagenen, Hurteau, et al. 1967). However, it would be misleading to say that simply guiding detached discovery was the chief reason for scientists' mechanistic interests. Instead, their main interest in this mechanism was over its relation to the ethics of reproduction and the politics of women's health. Mechanistic reasoning provided researchers with a distinctly moral form of guidance regarding their ethical codes, religious beliefs, and political goals. Developers of the pill were proponents of contraception regardless of when it worked, typically

\footnotetext{
${ }^{5}$ In contrast, Jeremey Howick (2011) argues that mechanistic reasoning is not a reliable heuristic because of its high cost-to-benefit ratio.
} 
for eugenics and population control. ${ }^{6}$ Detractors spurned late-acting pills as equivalent to abortion, which they condemned mostly for religious reasons (as Roman Catholics). As we shall see, reasoning about the mechanism of this drug-in-development crucially influenced research personnel, shaping the expertise and knowledge available or absent during early development.

For these advocates and critics of this pill, their prior collaboration during the 1950s framed their relationship and their interest in contraception. Biologist Min Chueh Chang (b.1908 - d.1991) and physician John Rock (b.1890 — d.1984) worked together to develop what became "The Pill" with the support and direction of the Worcester Foundation for Experimental Biology (WFEB) in Shrewsbury, Massachusetts. Chang was an experimental biologist trained at Cambridge, who began working at WFEB in 1945 on fertilization under the direction of cofounder Gregory Pincus (b.1903 - d.1967). Along with intellectual curiosity about the process of fertilization, personal eugenic concerns about unchecked population growth motivated the contraceptive research of Chang and Pincus (M. C. Chang 1968; Greep 1995).

Rock was also affiliated with Worchester, having conducted the Pill's preliminary human tests at his Massachusetts clinic and co-directed the later trials in Puerto Rico. For improving marital relations overburdened by children, this Catholic physician founded the first free birthcontrol clinic in Massachusetts in the late-1930s (Marsh and Ronner 2008, p. 147). Rock and Chang's collaboration with others, including feminist-eugenicist social reformers Margret Sanger

\footnotetext{
${ }^{6}$ Unlike the developers themselves, some of their collaborators and patrons were feminists committed to women's liberation, such as Margret Sanger and Katharine Dexter McCormick. Nevertheless, they were all motivated to some degree by eugenics and the need for population control (see Marks 2001; Marsh and Ronner 2008).
} 
and Katharine Dexter McCormick, paved the way for the first hormonal contraceptive Enovid, approved in 1960 (see Marks 2001; Tone 2001; Marsh and Ronner 2008).

Rock's support of hormonal contraception put him at odds with most other Catholic physicians of the day (see Williams 2016). Moreover, he deviated from Catholic teaching in his support of artificial contraception because of his understanding of its mechanism. In 1963 he published a widely popular book, titled The Time Has Come: A Catholic Doctor's Proposals to End the Battle over Birth Control. There, he argued that progesterone merely prevents ovulation to extend the natural "safe period" of infertility. Catholic social teaching allowed couples to use the natural method of infertile periods for family planning. Thus, Rock argued that a "pillestablished safe period" should have the same moral and theological implications (Rock 1963, pp. 168-69).

Nonetheless, apart from contraception, the Catholic social teaching that abortion is a mortal sin begins at fertilization when egg and sperm fuse. This stance relies in part on the ontological and ethical beliefs that, once a life has a human soul, it is a full human person and that ensoulment happens at fertilization, hence the "conception" of the person (see Miller 2014, pp. 60-63; Williams 2016, p. 12). This ontological issue of where a woman's body ends and another person's begins has ethical implications for bodily autonomy and its limits. Under Catholic teaching, ending the life of a zygote (fertilized egg) or more developed fetus constitutes the immoral killing of an innocent person and thus was prohibited at Catholic hospitals (NCCB 1971). Thus, entwined with the moral status of the zygote are the ethics and politics of motherhood, particularly the rights and responsibilities of women after fertilization, such as in the case of preventing pregnancy for rape survivors (Luker 1984; compare, e.g., Lynch 1977; McCarthy 1977). 
Rock believed in the moral legitimacy of abortion for the mother's health and even conducted experiments on zygotes and embryos. Nonetheless, he remained uneasy about elective abortion and was undecided about the precise timing of ensoulment (see Marsh and Ronner 2008, pp. 57, 241, 351 n.7). Most relevant to our story, Rock (1965) used mechanistic reasoning to appease other Catholic doctors who were more concerned about the risk of abortion (meaning termination after fertilization). The main action of progestins, he claimed, was to inhibit the release of an egg from the ovaries. While they do alter cervical mucous and limit endometrial glands, "there can be no question of an abortion if there is nothing to abort" (Rock 1965, p. 402).

While Rock was using mechanistic knowledge to defend this anovulatory pill, Chang sought more effective interventions with less of the side effects that were attracting medical and public concern (Watkins 1998). In 1959, he induced ovulation in rats and rabbits and then treated them after insemination with an antifertility agent (M. C. Chang 1959). Chang explained the observed "anti-zygotic activity" in terms of the compound's effect on the transport of fertilized eggs through the Fallopian tubes. During the mid-60s, his research team found the estrogen ethinyl estradiol (EE) to be the most effective in such interference in rabbits and hamsters (M. C. Chang 1964; M. C. Chang and Yanagimachi 1965; M. C. Chang and Harper 1966). To make birth control better and solve the "so-called population explosion," Chang thought, would require effective "day-after" solutions: "It is always better to reach a specific target than the whole system" (quoted in Lader 1966, p. 58). He targeted the embryo in transport rather than the higher nervous centers because the cognitive side effects (e.g., nausea, headaches, depression) "might be disadvantageous" for women's health (M. C. Chang 1967, p. 387).

But Rock disagreed that reaching this "specific target" of egg transport is "always better." In a 1966 interview for the New York Times on Chang's progress, he diverged with his old 
teammates and indicted their new approach: "I feel this pill is an abortifacient" (Lader 1966, p. 55). Despite having no objections to his own in vitro fertilization (IVF) experiments two decades earlier (Marsh and Ronner 2008, pp. 103-4), Rock would not support this post-coital pill, at least publicly. WFEB director Pincus responded that the new pill could not be abortifacient. Unlike the Catholic Church, the nascent American College of Obstetrics and Gynecology (ACOG) defined 'pregnancy' as beginning with implantation (see Section 3). Unlike in their previous collaboration, Rock's resistance limited WFEB's access to human subjects, so Chang stuck to his regular method of animal experiments in the lab. After Pincus's death in 1967, Chang left this anti-fertility work to focus more on facilitating pregnancy with IVF (M. C. Chang 1968; see Greep 1995).

Two Yale professors at the university's School of Medicine, however, did have access to human and non-human primates. Biologist Gertrude van Wagenen (b.1893—d.1978) was studying rhesus monkeys in one of the earliest captive colonies, which she began in 1935 (Fridman 2002; Rossiter 1982). She discovered that administering high doses of estrogen led to infertility. Van Wagenen brought this to the attention of her colony's clinical adviser, the gynecologist John Morris (b.1914-d.1993), who was interested in population control. Together they found that ovulation and implantation were absent after dosing monkeys with estrogens like EE and diethylstilbestrol (DES) (Kohorn 2009).

To inhibit implantation, the Yale group subsequently tested over 15 anti-fertility compounds in rats, rabbits, monkeys, and then humans, eventually settling on DES (Morris and Van Wagenen 1966; Morris, Van Wagenen, Hurteau, et al. 1967; Morris, Van Wagenen, McCann, et al. 1967). This synthetic estrogen already had approval of the US Food and Drug Administration (FDA) in 1941 for alleviating menopause symptoms, and it would remain on the 
market until 1971 when its carcinogenicity in humans was established (Langston 2010). In the meantime, the technology begun by Chang and continued by van Wagenen and Morris subsequently spread throughout student health centers and hospitals in the US (Prescott 2011).

In sum, during this initial period of research in the ' $60 \mathrm{~s}$, mechanistic reasoning functioned as guidance for individual researchers' moral decision making. The ethical and political relevance of the mechanism of the post-coital pill influenced who engaged in the research, why, and how they did it. Scientists with the goal of developing better population control such as Chang, Morris, and van Wagenen sought safer and more effective means of hormonal contraception. They figured that the Pill indiscriminately restructured women's menstrual functioning, likely causing unnecessary side effects and possibly comprising the effectiveness of population control because of discontinuation. Thus, they reasoned mechanistically to intervene more strategically and precisely on processes besides ovulation via post-coital administration. Contrasted with earlier combined-oral contraceptives that were taken regularly and suppressed ovulation, these new post-coital methods were intentionally designed to act later (on egg transport, fertilization, or implantation). Better to intervene later and more precisely, they thought, than to undermine the effectiveness of family planning and population control.

However, Chang's relatively safer formulation using EE was neglected by the Yale group, in part because of Rock's reticence over how the pill worked. His religious and ethical beliefs gave the mechanism special moral valence, such that interventions after ovulation were off-limits. Rock was willing to deviate from other Catholic physicians on the Pill because its action was on ovulation alone; nonetheless, he was uneasy with Chang's newer techniques, so he left the team. Accordingly, his expertise in running human trials abroad for the pharmaceutical 
company was no longer available. After Morris and van Wagenen took up the helm, they found both DES and EE to be effective, but they publicly promoted the use of DES (Scientific American 1966, p. 56). Despite their efforts to test for health harms, soon the safety of their procedure came under fire as the risks of DES surfaced (Hatcher and Conrad 1971; see Langston 2010). It is plausible that Rock's presence might have led to more testing in humans with EE, which is still used in lower doses for combined oral contraception. Regardless of the specific effect, Rock's moral qualms undercut his former team's ability to respond empirically to the Yale group.

Thus, this moral guidance builds on the more detached heuristic function of simply providing a strategy for discovery/development (from Craver and Darden 2013; Darden 2006; Solomon 2015); it too has epistemic consequences regarding expertise and methodology. Reasoning about post-coital mechanisms took on ethical, political, and religious significance, differently engaging the expertise of Chang (and eventually van Wagenen and Morris) toward intervention while disengaging Rock. Accordingly, it pointed their techniques toward more precise interventions over more general ones, while also altering their methods of treatment and access to research subjects. Reasoning about mechanisms provided a distinctly moral form of guidance, directly relevant to the research personnel's values about why effective post-coital contraception was desirable (for the goal of population control) or not (as an abortifacient means).

\section{A Scheme for Ethical Categorization: Abortion, Contraception, Both, or Neither?}

Moving from discovery to justification, we turn to the role of mechanisms in the clinical context. 
Many philosophers of medicine have discussed the evidential function of mechanisms in clinical practice, i.e., for justifying claims of therapeutic effectiveness for populations of patients (Clarke et al. 2014; Dragulinescu 2017; Howick 2011; Illari 2011, 2017; La Caze 2011; Russo and Williamson 2007, 2011, 2012; Thagard 1999). Philosophers often emphasize this evidential role for mechanistic knowledge in their critiques of evidence hierarchies. For instance, many advocates of Evidence-Based Medicine rank randomized clinical trials (RCTs) and systemic reviews of them at the top of the hierarchy of evidence and mechanistic studies at the bottom or off the chart (e.g., GRADE Working Group 2004; Guyatt et al. 2015). ${ }^{7}$ Cartwright and others contend that while RCTs can establish a causal connection between two factors given the satisfaction of study assumptions, mechanisms can provide some evidence of confounding and non-causal correlations (Cartwright and Hardie 2012; Howick 2011; Illari 2017). Going further, Russo and Williamson argue that both mechanisms and RCT statistics are "normally required" for causal inference, although neither is necessary nor sufficient (Russo and Williamson 2012, p. $250){ }^{8}$

\footnotetext{
${ }^{7}$ However, one should note that it not a hierarchy of evidence per se but of methodologies (Bluhm 2005). For a review of critiques of Evidence-Based Medicine, and an analysis of its proper place in medical epistemology, see Solomon $(2011,2015)$.

${ }^{8}$ This evidential function in the strong form advocated by Russo and Williams is more contested than the heuristic one. Medical researchers (e.g., Guyatt et al. 2015) and institutions (e.g., the Cochrane Collaboration) oppose it implicitly by omission from their hierarchies of evidence. Several philosophers argue against the evidential function of mechanism explicitly (Andersen 2012; Bluhm 2013; Broadbent 2011; Dragulinescu 2012; Solomon 2015), while others argue that
} 
I argue that, beyond the evidentiary role of mechanisms in the clinic, they can further assist clinicians in developing categories (or schemes) over ethically tumultuous terrain. Granted, the effectiveness of the morning-after pill depends on when it is taken during a woman's menstrual cycle, so clinicians have long emphasized the mechanism's importance for determining the period of effectiveness (e.g., Kesserü et al. 1974) and counseling individual patients (e.g., Grou and Rodrigues 1994). Yet, that is only part of the story: mechanistic knowledge took on a different clinical function within obstetrics and gynecology $(\mathrm{OB} / \mathrm{GYN})$ over categorizing the treatment, in part because of its technical novelty and its political currency as a tool of contested ethical quality during the era of legal reform around contraception and abortion. The liminal status of this new technology prompted clinicians to revisit the old definitions of 'contraception,' 'pregnancy,' and 'abortion' and to grapple with the uncertainty of the mechanism. In newfound clinical contexts, supportive scientists and medical professionals sought to separate the categories of post-coital contraceptive and abortifacient, while contraception critics and anti-abortionists, particularly Catholics, rejected this categorical scheme as ethically suspect. As we shall see, these divergent clinical categorizations reflected deeper divergences over how to control or promote women's health, and they had substantial effects on women's treatment options in hospitals.

When Morris and van Wagenen's procedure spread to clinics in 1966, it ushered in new concerns about categorization. Relaying this progress, Time Magazine described the pill as "not literally a contraceptive, since it does not work by preventing ovulation" like the other hormonal

the possible evidential import of mechanistic evidence can be outweighed by commercial forces (Holman 2017). 
methods available at the time (Time 1966). So, what is this new pill? Its ambiguous status took on legal significance in the context of contraception and abortion reform. In 1965, the US Supreme Court overturned state prohibitions of contraception as unconstitutional in the landmark case Griswold v. Connecticut. Other US state laws continued to prohibit substances intended to abort or miscarry; nonetheless, popular support for the legalization of abortion was swelling (CDD 1967). By the late 1960s, groups ranging from the American Medical Association to the American Baptist Convention supported legal access to abortion. The only organized opposition to legalization for abortion and contraception came from Roman Catholics, especially clergymen and physicians (see Burns 2005; Luker 1984; Williams 2016).

Scientists and family-planning professionals were acutely aware of this classification problem, which came to the fore in Santiago, Chile, during the 1967 conference of the International Planned Parenthood Federation (IPPF). The IPPF invited representatives from WFEB and Yale to the Global South to present their new results, which commentators agreed were very promising (Jackson 1967, p. 485; Parkes 1967, p. 505; Sjövall 1967, pp. 510-11). During the conference's closing session, after reports from Chang, Morris, and van Wagenen, Thorsten Sjövall (b.1913 — d.1998; Vice President of IPPF Europe and Near East Region) reflected on how the drug's ambiguous classification related to these progress reports' ethical significance (Sjövall 1967, p. 510). Rather than focusing on "the legally and ethically accepted definitions for the beginning of life" he suggested that ethical evaluations ought to prioritize "the subjective experience of the woman" (Sjövall 1967, p. 511). By shifting the focus from physiology to psychology, he reasoned that the post-coital pill might better be defined as a 'contraceptive' rather than an 'abortifacient' because women experience it working more like the former than the latter. 
To settle ambiguities such as these, OB/GYNs began to standardize terms. The ACOG (established 1951) released its first volume of terminology in 1972. Morris-one of the researchers from Yale — was a major contributor and consultant to the effort. The volume's definition of 'conception' aligned with the morning-after pill's developers: "Conception is the implantation of the blastocyst. It is not synonymous with fertilization. SYNONYM: Implantation" (Hughes 1972, p. 299). 'Pregnancy,' defined as "the state of a female after conception and until termination of the gestation," thus excluded the days before implantation (Hughes 1972, p. 327). And 'abortion,' listed as one of the "complications of pregnancy," also excluded inhibitory action prior to implantation (Hughes 1972, p. 414). This terminology provided an alternative ontological and ethical position to the growing "Right-to-Life" movement, spearheaded by Catholics, who defined 'the conception of life' and 'personhood' as beginning at fertilization and thus defended the rights of zygotes (Williams 2016).

Thus, Catholic OB/GYNs would now be using non-standard terms when calling the postcoital pill an 'abortifacient,' such as Rock had 6 years earlier. The secular OB/GYN discipline and the Catholic Church had developed competing categorical schemes, with 'pregnancy' beginning at implantation and fertilization, respectively. But what about this new pill? Chang and Pincus considered their pill simply a post-coital form of 'contraception' because it interfered with egg transport (Lader 1966, p. 55). The Yale group classified it differently, following the sentiments of Sjövall: what mattered was not only the physiological mechanism but also the ethical and cultural significance of "how it works." In 1973, Morris and van Wagenen proposed using the special category of 'interception' for preventing implantation (1973, p. 101). Two researchers had coined 'interception' a couple years prior because unlike 'abortifacient' it lacked undesirable psychological and ethical connotations based on "social background and moral 
taboos" (Naqvi and Warren 1971, p. 732). The Yale team thought that estrogen administered after intercourse did not interfere with ovulation or fertilization or after implantation but only with the process of implantation. Their treatment was not quite contraceptive (pace Chang and Pincus) nor abortifacient (pace Rock), but rather something novel operating in between. Thus, the ethical stakes of this innovative treatment shaped the development of clinical classifications and even promoted the development of a new concept.

Despite the legalization of abortion in various states and then at the federal level in 1973, the ACOG it could not simply define away the new social movement of "Right-to-Life" opposition to abortion. In their Ethical and Religious Directives for Catholic Hospitals, the US bishops prohibited physicians from providing and even discussing contraception and abortion. The 1971 edition of the Directives prohibited post-coital contraception, stating that preventing implantation via endometrial curettage (scraping the uterine wall) "is morally equivalent to abortion," even for treating women who had survived rape (NCCB 1971, dirs. $19 \& 24$ ).

As curettage gave way to hormones as the standard treatment after rape for preventing pregnancy, Catholics also debated the new treatment's ethical and clinical legitimacy, in part because of the uncertainty surrounding its mechanism. In 1977, The Linacre Quarterly — the official journal of the US-based National Federation of Catholic Physicians' Guilds — printed a point/counterpoint for and against DES as post-coital treatment of rape survivors. Catholic priest and theology professor Donald McCarthy defended the ethical permissibility of the drug, citing Morris and van Wagenen (1966) that it could act merely as an anovulant if given before ovulation. He contended that post-coital contraception would be justifiable after rape as a woman's self-defense "to counter the violence of the rape aggressor" (McCarthy 1977, p. 213). Thus, McCarthy was willing to allow the use of a hormonal treatment in the situation of rape- 
but only if working before fertilization to prevent pregnancy.

In his counterpoint, William Lynch (President-elect of the National Federation of Catholic Physicians' Guilds) objected, faulting McCarty for ignoring more recent work on the “interceptive” capacity of DES (i.e., Morris and Van Wagenen 1973). But unlike van Wagenen and Morris, this physician equated the new post-coital agent with abortion: "Interception by any other name is abortion” (Lynch 1977, p. 228). In response, McCarthy held his ground by objecting to Lynch's standard for certainty: "As with all contraceptive drugs, it is difficult to prove absolutely that ovulation has been blocked in each individual cycle despite their known contraceptive effects" (McCarthy 1978, my emphasis). Like Rock previously, these Catholics valued knowledge about the mechanism for its ethical, ontological, and religious relevance to abortion and reproductive health. In contrast with Rock's disinclination to research, their values motivated a disinclination to use and prescribe the now-available pill if it acted (or might act) in a certain way. Even for Catholics who prioritized women's interests, such as McCarthy, the mechanism of treatment could preclude its ethicality when fertilization had occurred. Furthermore, the uncertainty of its mechanism took on heightened significance where the bishops' Directives left little room for any form of contraception and banned treatments categorized as 'abortifacient.'

Following McCarthy, the subsequent edition of the Bishop's Directives allowed for hormonal treatment in hospitals but only to delay ovulation, thus necessitating a pregnancy test and testimony from the woman about her cycle (NCCB 1995, dir. 36). While seemingly tolerant and possibly even favorable of contraception, the abortion-rights group Catholics for a Free Choice (CFFC) conducted an undercover survey and found otherwise: this rule resulted in more than 4 out of 5 Catholic hospitals never providing post-coital pills to women and less than 1 out 
of 4 offering referrals elsewhere (Bucar 1999). At that time, Catholic hospitals were more likely than non-affiliated hospitals to prohibit discussion, prescription, and dispensation of this treatment to rape survivors, despite its status as the medical standard of care (Smugar et al. 2000). CFFC distributed its results to over 30 media outlets to shame the Catholic hierarchy and motivate reform (Miller 2015, pp. 174-89).

In sum, the novelty of the technology and the legal stakes of contraception and abortion encouraged physicians to develop new classificatory schemes. Their ethical and religious values mediated how they used their knowledge of the treatment's mechanism to define what it was and to distance it from what it was not. To avoid the connotations of 'abortion,' pro-contraception scientists and physicians sought to distance the post-coital pill as merely a 'contraceptive' or 'interceptive.' Anti-abortion Catholics rejected the ACOG's definitions as ethically suspect, but Catholic advocates of women's rights defended the morning-after pill either for limited use (McCarthy) or as a necessary component of women's health care (CFFC). Related to their different ontological commitments, these different schemes highlight divergent conceptions of women's reproductive health, either prioritizing women's agency or circumscribing it to her procreative ability. Furthermore, the disagreement within each group resulted from their different values and the empirical uncertainties of the drug's mechanism.

Reflecting on this historical episode, we see how the clinical function of the mechanism went beyond justifying claims about effectiveness or even counselling patients accordingly—the evidential functions discussed extensively by existing philosophical accounts (Clarke et al. 2014; Dragulinescu 2017; Howick 2011; Illari 2011, 2017; La Caze 2011; Russo and Williamson 2007, 2011, 2012; Thagard 1999). Instead, understanding the mechanism and the uncertainties surrounding it factored into debates over treatment categorization and prompted the expansion of 
old categories like 'contraception' and the development of new concepts like 'interception.' Classifying the morning-after pill was not simply a dispassionate or abstract enterprise but a thoroughly ethical one with concrete stakes involving early stages of human life, treatment for rape survivors, and women's rights. It pitted Catholic OB/GYNs against non-Catholics, but it also elucidated conflict within each group because of different values and uncertainties. As we shall see, struggles surrounding the mechanism and patients' access only increased as the drug became more widely available outside the oversight of physicians.

\section{A Political Instrument for/against Access and Agency}

Finally, we move from justification in the clinic to application in the wider realm of government and healthcare policy. When going beyond the lab and the clinic, philosophers of science have acknowledged that mechanistic knowledge has the practical potential to enable control — both of biology (Craver and Darden 2013) and society (Cartwright and Hardie 2012; Russo 2012; Russo and Williamson 2012). Mechanistic knowledge has allowed humans to intervene on causal processes with treatments targeting the various links of the causal chain, e.g., attempts to cure or manage cystic fibrosis via therapy of genes, transcription factors, protein synthesis, or immune response. Craver and Darden call this the "pragmatic value of knowing how something works" (2013, pp. 186-95, my emphasis; see also Au 2016). Russo (2012) argues that evidence of mechanisms also provides policy makers relevant information about the available causal pathways for intervention so that they act on factors that are both causal and manipulable, rather than spurious and inaccessible (see also Russo and Williamson 2012; Marchionni and Reijula 2019). Cartwright and Hardie (2012) argue that while RCTs can decisively "clinch" conclusions about treatment effectiveness at a trial, they do not provide answers to information about process, 
which is necessary for successfully predicting whether/how a treatment will work elsewhere. Thus, to make reliable predictions about policy-effectiveness, they suggest policy makers reason mechanistically about the steps required and processes responsible for such effectiveness (see also Cartwright and Stegenga 2011). For instance, writing the steps from start to finish can help policy makers identify relevant support factors, and diagramming processes fleshes out implicit assumptions and potential negative feedbacks. ${ }^{9}$

Nevertheless, as well shall see, the control afforded by mechanistic information goes beyond making effective interventions and policy predictions. These proposals intimate the social power of mechanisms, yet we can go further: this section describes how mechanistic information can factor into economic and legal skirmishes as an instrument of social power itself. In the arena of governmental regulation, both advocates and critics of the morning-after pill used mechanistic knowledge instrumentally to increase or limit women's access to this treatment. Anti-abortion science advisers in the US advocated for labeling the morning-after pill Plan B as having a possible post-fertilization mechanism, and others later used this label to limit women's insurance coverage. Contemporaneously, envisaging similar barriers in the majorityCatholic country of Chile, pro-contraception scientists designed experiments to pinpoint the mechanism, reduce uncertainty, and promote access to the drug. Beyond utilizing or predicting effectiveness, these scientists and physicians throughout the Americas leveraged mechanistic information for or against women's agency in medicine. To contrast the strategies of anti-

\footnotetext{
${ }^{9}$ Nonetheless, some philosophers have condemned such attempts to generalize or extrapolate from mechanistic knowledge as dubious because of the instability of mechanisms across populations (Howick 2011; see also La Caze 2011).
} 
abortionists and women's health advocates, this section begins with the US case and then moves to Chile.

Following the discovery of the carcinogenic risks of DES in the early-70s (Hatcher and Conrad 1971), researchers around the world developed alternatives to estrogen, including a progestin-only formulation using levonorgestrel. Women's health advocates led by Sharon Camp sought to increase access to this new formulation, founding the International Consortium for Emergency Contraception (ICEC) in 1995. However, concerns about the allegedly abortifacient mechanism had a market-chilling effect, creating problems for the ICEC in Australia, Burma, Chile, Great Britain, Mexico, the US, and elsewhere (Foster and Wynn 2012; Prescott 2011).

As part of ICEC's campaign to streamline approval abroad, Camp submitted an application for "Plan B" to the FDA, which was approved in 1999. However, women's health advocates were unsatisfied with access limited to prescription holders and adults (18+) restrictions they considered "special paternalistic scrutiny" without scientific or legal justification (Ellertson et al. 1998, p. 229). Thus, to expand women's access to this “back-up birth control" (hence, Plan B), Camp applied for non-prescription sale over-the-counter. At the 2003 science advisory meeting, the pharmaceutical sponsor argued that the active ingredient levonorgestrel does not act after fertilization, rendering the drug "an oral contraceptive, not an abortion pill” (FDA 2003, p. 31).

Committee member Joseph Stanford balked at this anovulatory characterization. A professor of family and preventive medicine at the University of Utah, Stanford was a Catholicinfluenced Mormon physician who believed human life (and personhood) begins at fertilization (Larimore et al. 2004; Stanford 2011). He claimed that post-fertilization action was possible because of the capacity of the drug to act five to six days after treatment. Therefore, it was 
ethically necessary to communicate this possibility to patients for their informed consent (FDA 2003, p. 271; Larimore and Stanford 2000; Kahlenborn et al. 2002). Despite alternative interpretations of the research, five committee members supported a label on the outside carton to inform patients "at the point of purchase" (FDA 2003, pp. 319, 398-411).

The committee approved over-the-counter sale (4-NO against 23-YES), but the FDA retained Plan B's prescription-only status for almost three years because of conservative and religious opposition, including anti-abortion resistance (Wynn and Trussell 2006; Prescott 2011). In response to the objections of Stanford and two other advisers (2004), the pharmaceutical company included the mechanism in boldface on the final 2006 label as a "Drug Fact": "this drug works mainly by preventing ovulation (egg release). It may also prevent fertilization of a released egg (joining of sperm and egg) or attachment of a fertilized egg to the uterus (implantation). See consumer information leaflet." (FDA 2006, my emphasis). This unique drug label is the only instance describing a mechanism on the carton, and it was later added to the FDA website alongside the mechanisms of other forms of birth control (FDA 2013).

The FDA's official information about the mechanism had substantial effects on women's insurance coverage through the Burwell v. Hobby Lobby Stores, Inc. (2014) case. The craft store Hobby Lobby and the Christian bookstore Mardel claimed that governmentally required services such as Plan B were abortifacient and thus sued the government for violating their "religious freedoms." The plaintiffs relied on FDA information about how Plan B works, and the court allowed them to refuse coverage for their employees as part of their religious rights (Supreme Court of the United States 2013, n. 6, 2014, n. 7). Thus, while the science advisors like Stanford had justified this label to support the agency of patients and satisfy their "right to know" (FDA 2003, pp. 405-8), it had a different effect in court. The authoritative information gave anti- 
abortionists a political instrument with legal currency to support the agency of would-be providers to refuse women the drug.

In contrast to this case in North America, around the same time in South America, we see how women's health advocates utilized mechanistic knowledge as a political instrument for women's access and agency rather than against it. In Chile, the advocates of women's health foresaw the potential for information about the mechanism of emergency contraception to limit women's access (Schiappacasse and Díaz 2012). Because of the religious opposition to researching fertility control at the Pontificia Universidad Católica de Chile, physicians Horacio Croxatto (b. 1936) and Soledad Díaz established the Instituto Chileno de Medicina Reproductiva (ICMER) in 1985 in Santiago. They aimed to satisfy "the growing need for effective means to allow people to replace 'all the children God wants to give me' for 'all the children I responsibly want and can have"” (translated from Croxatto 2005).

A decade after leaving the Pontificia Universidad, Díaz discovered that the acceptability of emergency contraception in Chile hinged on reversing the negative perception of its being "microaborto" (a "micro-abortion" acting after fertilization) from Catholics and conservatives (Díaz et al. 2003a, 2003b). In 2001, immediately following approval of the first dedicated morning-after pill in Chile, the Corte Suprema banned their manufacture and provisioning. This decision was based on the Chilean constitution's explicit protection of "la vida del que está por nacer" (the life of the unborn) (Schiappacasse and Díaz 2012).

The literature available at that time on the mechanism of progestin-only emergency contraception was rather convoluted, especially regarding post-fertilization. Many studies evidenced the ability of post-coital levonorgestrel to delay or suppress ovulation (e.g., Spona et al. 1975; Garmendia et al. 1976; Landgren et al. 1989; Durand et al. 2001; Hapangama et al. 
2001; Marions et al. 2002). However, its effect on fertilization was not as well studied or evidenced (limited to Kesserü et al. 1974, 1975), and its effects on implantation were difficult to replicate consistently (for positive findings, see Landgren et al. 1989; Moggia et al. 1974; Shirley et al. 1995; Ugocsai et al. 1984; for negative findings, see Durand et al. 2001; Marions et al. 2002). This mixed state of the evidence enabled several scientific reviewers (including Stanford in the US) to claim that post-coital progestin might act after fertilization and that patients and providers deserve to know such (Kahlenborn et al. 2002; Larimore and Stanford 2000; Wilks 2000).

Croxatto disagreed with these interpretations of the evidence, pointing instead to the earlier mechanisms of inhibiting ovulation and sperm migration (Croxatto et al. 2001). Previous studies had relied on indirect measures of embryological development, such as trial statistics, endometrial receptivity, and hormones levels. In contrast, using different timings of levonorgestrel administration, ICMER researchers made more direct measurements of development, including the number of eggs ovulated, fertilized, and implanted in rats (Müller et al. 2003); follicle size and pregnancy in Cebus monkeys (Ortiz et al. 2004); and follicle size in humans (Croxatto et al. 2004). In all three studies, they found this progestin inhibited or suppressed only ovulation —not fertilization or implantation. After the 2004 double-blind trial in humans, Croxatto considered the results definitely supportive of pre-fertilization mechanisms (Population Council 2005).

Nonetheless, ICMER's work was insufficient to convince beyond a reasonable doubt the Tribunal Constitutional in 2008 that this drug could not work after fertilization; therefore, the court effectively banned public provisioning of emergency contraception because of the mechanism (Schiappacasse and Díaz 2012). While unsuccessful in Chile, ICMER's work 
promoted further study that confirmed their findings (e.g., Lalitkumar et al. 2007). The empirical uncertainty of this pill's mechanism seems to have lessened over time, particularly as some antiabortionists have come to reject a post-fertilization effect (e.g., Austriaco 2007). However, the controversy remains unresolved in much of North and South America, with a powerful minority of anti-abortionists continuing to assert the possibility of a post-fertilization effect based on different standards of evidence (e.g., Kahlenborn et al. 2015). ${ }^{10}$

The situation is different in Europe. Based on these empirical developments, the ICEC issued joint report with the International Federation of Obstetrics and Gynecology that concluded levonorgestrel works by inhibiting ovulation and maybe fertilization but "cannot prevent implantation of a fertilized egg. Language on implantation should not be included in [levonorgestrel emergency contraceptive pills] product labeling” (FIGO and ICEC 2011). Accordingly, the French manufacturer of the levonorgestrel-only pill NorLevo removed reference to implantation in its information leaflets for doctors and patients (HAS 2015). Part of the reason for this discrepancy between Europe and elsewhere is the relatively lesser political clout of anti-abortionists and the Catholic Church in much of the continent. The supporters of the morning-after pill in Chile also sought to quell political opposition by producing mechanistic knowledge for women's access and agency. Croxatto and Díaz granted the importance of patients' values but were not willing to obstruct access without what they took to be strong evidence against post-fertilization action.

In these governmental arenas, the role of mechanistic knowledge was pragmatic but

\footnotetext{
${ }^{10}$ While beyond the scope of this paper, I think that such standards are empirically unsatisfiable and thus deceptive.
} 
beyond the specific sense offered by philosophers of predicting or intervening effectively through treatment and policy (Cartwright and Hardie 2012; Cartwright and Stegenga 2011; Craver and Darden 2013; Darden 2006; Marchionni and Reijula 2019; Russo 2012; Russo and Williamson 2012). Instead, scientists leveraged knowledge about the mechanism in regulatory battles as epistemic means for their political goals. They saw the legal and political utility of information about mechanisms, either for or against access, and as science advisers or researchers they produced and promulgated those forms of information for governmental bodies. The US opposition used its mechanistic knowledge to create warning labels about postfertilization possibilities. Corporations later used this information to challenge their legal obligation to provide such pills in order to protect their "religious freedom" and the zygotic life they considered to have legal and human rights. In turn, the information disabled women as patients and consumers by restricting their coverage and access. In contrast, Chilean advocates challenged these claims with a carefully designed set of experiments, which ultimately influenced the labeling in Europe. In both episodes, values mediated how scientists used their knowledge of the mechanism: either to protect the agency and economic interests of would-be providers or to increase women's access and agency. Mechanistic information provided scientists a political instrument for achieving their political goals, again showcasing how knowledge about mechanisms is used for more than immediate therapeutic effectiveness.

\section{A Broader Scope for Understanding Mechanisms}

Having moved back and forth between the abstractions of philosophy and the particulars of history, this paper analyzed the production and use of mechanistic knowledge through several episodes in labs, clinics, and beyond. This section reflects on this HPS iteration and the 
challenges it raises for existing philosophical accounts. As we've seen throughout, the philosophical conversation on mechanisms is ready to be expanded. To recapitulate: rather than merely providing a heuristic for discovery, reasoning about mechanisms offers moral guidance when considering intervening on a process related to ethics or politics (Section 2). Aside from its possible evidential import for justifying effectiveness, knowledge about mechanisms informs clinicians in their categorization of treatments by relating medical definitions to their ethical connotations and political stakes (Section 3). Finally, instead of functioning as a tool only for making effective applications and policy, mechanistic information can also factor into political struggles as an economic and legal tool for achieving certain goals and undermining others (Section 4).

Because philosophers wish to provide practical and applicable accounts of mechanism, the time has come to broaden our scope to attend to the variety of challenges faced by scientific practitioners, physicians, and policy makers. While the three proposals of philosophers (heuristic for discovery, evidence of effectiveness, and instrument for effective control) provide important insights into scientific practice, they constitute a limited set of the possible reasons that researchers, clinicians, and institutions take mechanisms to be important. The limitation itself points to a deeper issue about our philosophical scope. The existing accounts of mechanisms focus the imminent and proximate issue of a drug's effectiveness: either creating, understanding, or utilizing treatments that produce a desired effect. Mechanistic reasoning does often shape scientific practice toward effective treatments; however, we have seen how scientific and social interests in mechanistic knowledge do not always arise from desires to develop effective drugs, justify claims about their effectiveness, or plan effective interventions. The next step in the philosophy of mechanisms is to articulate the broader function of mechanistic knowledge and 
reasoning. Typified by these episodes in the history of the morning-after pill, a more holistic and contextual understanding should attend to human values and the social aspects of biomedicine and health policy.

Across these historical episodes, we have seen how mechanistic reasoning relates not only to whether a treatment produces an effect that is desired, but whether, when, and why that effect and that treatment are desirable in the first place. In so far as knowledge of a drug's mechanism relates only to therapeutic effectiveness, one must take for granted the desirability of the effect and thus the desirability of having an effective treatment. That is, if it remains uncontested that an effective treatment is wanted or needed regardless of the physiological mechanism, then the existing functions proffered by philosophers might suffice. A simple example might be cancer, which easily evinces widespread public contempt and has even provoked the so-called "War on Cancer." If all is fair in love and war, then the means by which we battle cancer matter little apart from their potential for victory (i.e., effectiveness). For simplified cases of uncontested targets, it is possible that scientists could strive to make the treatment happen, thinking about mechanisms without moral reflection or political implications.

However, when the treatment itself is contested as a legitimate form of medicine or politicized otherwise, then we need to go beyond effectiveness to understand the holistic and contextual significance of mechanistic reasoning. The "War on Cancer" is a telling example: industry and anti-regulation advocates designed this wartime rhetoric to motivate streamlined approval for cancer treatment and to distract from preventative policies that would reduce industry profit (Coleman 2013; Davis 2007). Furthermore, we need to think more broadly and critically about what 'effectiveness' even means. The case of the morning-after pill supports these imperatives. Emergency contraception is desired by many for improving women's health 
and increasing self-determination, in part because their ontological and ethical beliefs about women's bodies encourage effectiveness after fertilization. However, this very form of treatment is contested by others for its temporal proximity to abortion and its physiological potential to act indiscriminately after an ontological change that they deem ethically significant (namely, fertilization). Since knowledge about mechanisms is important for defining technologies as 'contraceptive,' 'abortifacient,' or otherwise, biological mechanisms are integrally connected with value-laden ontological and ethical beliefs. When intervening on causal processes carries such societal stakes, we should expect mechanistic knowledge and reasoning to connect with these other aspects of human life involving norms and values.

We are now well posed to reorient the philosophical discussion about the production and use of mechanistic knowledge. Certainly, as philosophers have been arguing, "mechanisms matter!" Yet, as we've seen throughout these episodes with the morning-after pill, interest in the mechanism of action ultimately derives from how knowledge about it allows us to understand, promote, or control health for individual patients and society. Thinking mechanistically involves the potential to reorder human individuals and societies toward normal and normative states, with all the social norms, ethical values, and political stakes such interventions entail. In the case of women's reproductive health, medicine is clearly a thoroughly ethical and political enterprise (Wynn and Trussell 2006). Many view contraception and abortion as constitutive of women's health, but access to these treatments remains under constant threat throughout the world (Foster and Wynn 2012). In the US, the courts have reduced federal requirements for insurance coverage of contraceptives while state legislatures continue to chip away at the number of abortion facilities and providers with overly burdensome regulations (Guttmacher Institute 2018). This study suggests philosophers ought to consider the broader functions of mechanisms 
for scientists, patients, providers, policy makers, and society—particularly if we want to do more socially relevant philosophy of science (Fehr and Plaisance 2010; Weaver 2017).

Now, one might wonder about the extent to which this need for a broader scope can be generalized beyond or abstracted from my case study and the context of women's reproductive health. When must we go beyond effectiveness to understand the production and use of mechanistic knowledge? How frequently does mechanistic reasoning involve these humanistic and cultural issues? Rather than generalizing from a single case, I have sought instead to bring new perspectives to our understanding of mechanisms that are cogent and broadly applicable (see H. Chang 2011). Thus, I aim to go beyond my case study and the context of women's reproductive health to mechanisms in science and medicine more broadly. To show that my argument is about specifically mechanistic knowledge (and the associated philosophy of mechanisms) rather than any politically or ethically relevant knowledge in science, I need make the case for its applicability within that class of knowledge. ${ }^{11}$ I will make this case using three issues that span across biomedicine and health policy, beginning with early-life and near-death interventions and ending with pharmaceutical development. These examples encompass embryology, cardiology, neurology, pharmacology, and translational medicine.

First, the production and use of mechanistic knowledge in human-embryo research (e.g., IVF, embryonic stem cells, and cloning) shares many features with the morning-after pill, illustrating the prevalence of such issues throughout embryology and reproductive health. For instance, during the 1980 s and ' 90 s, mechanistic reasoning about the timing of conception

\footnotetext{
${ }^{11}$ I thank David Teira and Ashley Graham Kennedy for suggesting this objection and possible responses.
} 
provided similar moral guidance for/against intervention during the spread of IVF clinics. Subsequent ethical oversight of such practices prompted the creation of the new category of 'preembryo' (or, not quite an embryo) referring to the first 14 days after fertilization, with mechanistic knowledge again aiding categorization for clinics over ethical terrain. The National Institutes of Health's "14-day rule" limits research on human embryos beyond the point of gastrulation, following resistance from advocates of embryos' human rights. The rationale behind the rule was "pluralistic" and mechanistic: this biologically significant point of transition served as a compromise between those with different values regarding prenatal life (see Hurlbut 2017).

Like early-life interventions, the desirability of near-death treatments also turns on issues surrounding the parts of the process. The controversies over brain death illustrate how mechanistic reasoning outside embryology and reproductive health relates to ethical and cultural values other than when life begins. In the late 1960s, doctors faced new ethical concerns about organ transplants and life support. An ad hoc committee at Harvard Medical School influentially argued that the medical definition of 'death' ought to be the cessation of neural activity (hence 'brain death') resulting in an irreversible coma, rather than the traditional definition based on the cessation of cardiovascular activity. The committee justified this novel criterion for death based on the decreased suffering of family members and those seeking organs as well as the need for a new criterion for terminating life-sustaining treatment (Rothman 2003). While widely accepted in the US and elsewhere, not everywhere followed so quickly, particularly in Japan and Israel. In traditional Japanese culture, death was observed as a communal process. Thus, rather than a single moment in an individual's life, a person's death was a recognition of this change by their community that extended in time. Public resistance to assimilating the Western concept of brain 
death was based in part to these divergent values and norms related to personhood and death (Hoshino 1993; Nudeshima 1991). In Israel, as a comparison, there were controversies over interpreting authoritative Jewish texts regarding the definite signs of life, such as breath, heartbeat, and procreation. One crucial consideration was whether 'death' involved loss of blood flow to the head, rendering it a biological process like decapitation, which was widely viewed as a sign of certain death (Gross et al. 2018). Across these contexts, we see how mechanistic reasoning about the process of death involved ethical issues, like the termination of lifesustaining treatment, and cultural norms, like the recognition of death by one's community.

Outside issues common in bioethics, the design and structure of biomedical research illustrate how pharmaceutical companies use mechanistic knowledge for financial gain. Consider the design of surrogate endpoints, which researchers use to evaluate the effectiveness of drugs in the place of more patient-relevant outcomes like morbidity and mortality. The possible therapeutic significance of mechanisms for evidencing effectiveness via surrogate endpoints can be outweighed by commercial pressures. Why? Systemic problems with industry funding can overwhelm our knowledge base without corrupting the reasoning of individuals (Holman and Bruner 2017). For instance, during the 1980s, anti-arrhythmic drugs became popular treatments for patients who had suffered heart attacks. The trials evidencing their effectiveness, however, were based on the endpoint of suppressing arrhythmias rather than reducing deaths. While nearly all arrhythmias were harmless, a substantial portion of heart attacks were precipitated by them, which researchers and physicians took as evidence of their key role in the process. (They reasoned mechanistically that when the ventricle contracts arrhythmically with an extra beat before it has time to refill, it could at times damage the lungs, brain, and kidneys and ultimately lead to the mortality risk observed.) However, Bennett Holman (2017) has argued that the 
surrogate endpoint gained credence not simply on the ground of mechanistic reasoning: more instrumentally, the drug industry shaped the medical discussion by manufacturing expert consensus over it for FDA approval. By supporting researchers with pro-industry results, the drug sponsor amplified the impact of commercially favorable articles to promote this lucrative mechanistic knowledge. While there was a body of evidence supporting the arrhythmiassuppression mechanism, this evidence itself was the result of sustained pressure from industry to justify the use of these drugs. Therefore, the very category of 'effectiveness' has economic value that influences how mechanistic knowledge is produced and used.

This case of the commercialization of mechanistic knowledge might seem ethically or epistemically vicious. Nonetheless, such uses (or abuses) of mechanistic reasoning are common in "translational medicine," which aims to expediate the time "from bench to beside" (Solomon 2015). Drug companies have partnered with universities to secure governmental funding of "basic research" on mechanisms and to externalize the costly risks of early development—all while still securing knowledge with commercial potential for new markets down the road (Robinson 2018). Because of the entanglement of commercial and medical interests, biomedical researchers and their industry benefactors can utilize mechanistic reasoning to make dubious claims about therapeutically irrelevant effectiveness for financial gain. Commercial pressures also disincentivize less lucrative forms of mechanistic reasoning. In the case of bacterial resistance to antibiotics, Ashley Graham Kennedy (2018) argues that developers could utilize the mechanisms of evolution to re-sensitizing bacteria that have acquired antibiotic resistance and recycle old drugs. However, industry appears to be ignoring this mechanistic knowledge because of the financial incentives for creating new drugs and markets.

In sum, the cultural norms, ethical values, and economic currency associated with 'life,' 
'death,' and 'effectiveness' shape mechanistic reasoning in the design and use of pharmaceuticals and other treatments. This variety of examples suggests that well beyond the morning-after pill and outside women's reproductive health, it is common for the desirability of drugs to hinge on their mechanisms.

\section{Socially Relevant Medical Epistemology}

This analysis provides a constructive expansion on the existing work from philosophers, who have already done much to explain the epistemic and methodological significance of mechanisms in science. Philosophers have illustrated the many ways that societal values actually and inevitably shape scientific research and science policy, for better and for worse (ChoGlueck 2018; Douglas 2009; Elliott 2011; Kitcher 2011; Longino 1990; Weaver 2017). Likewise, this paper attempts to broaden the existing scope of philosophies of mechanism by providing a richer description of how mechanistic knowledge functions in biomedicine and health policy. Accounting for social forces improves our understanding of the value-laden dimensions of scientific reasoning and how they vary across context, specifically for mechanisms (see Holman 2017; Kennedy 2018; Robinson 2018). This descriptive project aims ultimately at the more normative and critical one of improving how contextual values function in biomedicine and health policy. While direct guidance is beyond purview of this paper, it does have several implications regarding the philosophy of science and values, research ethics, science pedagogy, and science advising, which I will discuss briefly.

Values have distinct implications for medical epistemology about mechanisms. In several ways, we have seen how values generate "epistemic friction" by influencing what scientists and 
physicians know about mechanisms, how they produce that knowledge, and how they use it. ${ }^{12}$ For instance, concerns about the morning-after pill's mechanism altered the expertise and knowledge either available or absent during early development. Personal moral values (and differences between them) have direct consequences on the methods available to a lab for how it could intervene, such as the absence of Rock's background with human trials and the availability of Chang's proficiency with non-human animals. Furthermore, scientists can be inclined to intervene more specifically and at one point rather than another because of the moral valence of one part of a causal process, such as fertilization for its desired contraceptive capacity or its feared abortifacient potential.

The implications of values in clinics were different but no less definite. The ethical and religious beliefs of clinicians and healthcare institutions promoted the development of new concepts and categories. These values not only limited knowledge production but more proactively molded it toward certain norms of health, such as with liminal, ethically ambiguous concepts like 'interception.' Moreover, as treatments spread and the number of users and providers increases, there is a richer diversity of value judgments over how to handle uncertainties. This can lead to disagreement among those with similar beliefs, as we saw with women's health advocates, anti-abortionists, and Catholics.

Values in governmental contexts have different effects. Political battles create feedback effects on the production of knowledge about mechanisms, and mechanistic interests prompt scientists and physicians to act as advocates by promulgating specific forms of information for

\footnotetext{
${ }^{12}$ I thank Robyn Bluhm, David Teira, and an anonymous reviewer for pressing me to expound on these epistemic implications of value-ladenness.
} 
governmental bodies and producing new sorts of knowledge. Researchers' values are embodied in their standards of evidence, but their standards must pass legal muster to accomplish their desired political goals. Compare Stanford's anti-abortion advocacy as an adviser in the FDA with Croxatto and Díaz's pro-contraceptive advocacy as researchers in a mostly Catholic context. The former found the available evidence enough to support his position against the pill, and he could justify his standard of evidence based on the generally accepted right of patients to know. The latter, in contrast, were unsatisfied with the evidence and thus produced new knowledge with more exacting methods to pinpoint the mechanism step-by-step. Yet, their standard of evidence was insufficient in Chile given the legal protections for the rights of the unborn.

Beyond its intellectual contributions, my analysis also has broader implications for society at large. While contraception and abortion are common topics for bioethicists, they have not attracted the attention of philosophers of science and medicine, potentially seen as primarily ethical issues without epistemic relevance. Such an assumption would be wrong, but it would also be androcentric by overlooking women's widespread use of contraception and its necessity as an essential medicine (Daniels, Jones, et al. 2013; Daniels, Mosher, et al. 2013; WHO 2017). Furthermore, it would render our philosophy socially irrelevant and impotent for making meaningful attempts to understand and improve medicine. As Holman (2017) argues, a "frictionfree epistemology" that abstracts from sociological forces is not very helpful for capturing the real-world pressures that are constitutive of medicine.

In contrast, this sort of study can inform critical efforts in research ethics and science pedagogy. For instance, in labs with ethically and politically sensitive objects of inquiry, these real-world examples enable students and practitioners to see how mechanistic reasoning relates to questions beyond immediate effectiveness for reaching some given endpoint. Creative 
approaches to ethics education are crucial for developing scientists' epistemic and moral responsibilities beyond their personal values and individual responsibility (Douglas 2014; Rolin 2017). This analysis guides us through rethinking the criterion of effectiveness as not necessarily desirable and probing the connections between ontology, ethics, politics, and epistemology. These historical episodes can help researchers and students contrast alternative values and point to previous ways of handling difficult issues. Accordingly, they can learn how to connect the different layers of mechanistic reasoning, including normative dimensions, and consider the possible epistemic and practical consequences downstream.

In addition, this analysis illustrates the epistemic means by which science advisers can attempt to influence governmental agencies and the courts, particularly how they can succeed and fail as advocates. While philosophers of science have sought to provide practicable guidance for science advisors (e.g., Douglas 2009; Steele 2012), their suggestions of avoiding wishful thinking and implementing rational decision theory do not address some of the political realities of the contentious advisory process. For one, science advisors wield significant political power in policy making, akin to a "fifth branch" of government (Jasanoff 1990). At the time of the FDA labeling, anti-abortion advisers expressed concerns for the rights of women as consumers who were opposed to abortion. Yet, their label's larger achievement for anti-abortionists was in advocacy for the rights of employers to refuse insurance coverage based on "religious freedom." Second, this analysis illustrates the need for the courts to reconsider the seeming value-freedom of information. "Drug Facts" produced by the FDA can be value-laden with special interests, such as how anti-abortion advisers advocated for a warning label to protect zygotic life. Because of how its authoritativeness overshadowed its political function, this mechanistic knowledge effectively restricted women's healthcare options and agency. 
If we want to practice socially relevant philosophy of science, the time has come to connect medical epistemology with the cultural and value-laden aspects of biomedical research and clinical practice as well as the politics of health (Fehr and Plaisance 2010). Such links are important for understanding drug development, where industry wields significant power, and particularly for reproductive health, where conflicting values and gender politics limit women's access and agency. As scientists develop new means of contraception and abortion, these technologies will continue to be evaluated according to these shifting social stakes that hinge in part on the mechanism of action. Epistemology in context and in practice is full of contentions, but so is medicine. By accounting for the specific challenges that arise with mechanistic reasoning, we can take another step toward tackling them. 


\section{References}

Andersen, H. (2012). Mechanisms: What are they evidence for in Evidence-Based Medicine. Journal of Evaluation in Clinical Practice, 18(5), 992-999.

Au, Y.C. (2016, April 28). Synthesising heterogeneity: trends of visuality in biological sciences circa 1970s - 2000s. Doctoral dissertation. University College London. http://discovery.ucl.ac.uk/1478180/. Accessed 31 August 2018.

Austriaco, N. P. G. (2007). Is Plan B an Abortifacient? The National Catholic Bioethics Quarterly, 7(4), 703-707.

Bechtel, W., \& Abrahamsen, A. (2005). Explanation: A mechanist alternative. Studies in History and Philosophy of Science Part C: Studies in History and Philosophy of Biological and Biomedical Sciences, 36(2), 421-441.

Bluhm, R. (2005). From hierarchy to network: A richer view of evidence for evidence-based medicine. Perspectives in Biology and Medicine, 48(4), 535-547.

Bluhm, R. (2013). Physiological mechanisms and epidemiological research. Journal of Evaluation in Clinical Practice, 19(3), 422-426.

Broadbent, A. (2011). Conceptual and methodological issues in epidemiology: An overview. Preventive Medicine, 53(4-5), 215-216.

Bucar, E. (1999). Caution: Catholic health restrictions may be hazardous to your health. Washington, D.C.: Catholics for a Free Choice.

Burns, G. (2005). The moral veto: Framing contraception, abortion, and cultural pluralism in the United States. Cambridge, England: Cambridge University Press.

Cartwright, N., \& Hardie, J. (2012). Evidence-Based Policy: A practical guide to doing it better. Oxford: Oxford University Press. 
Cartwright, N., \& Stegenga, J. (2011). A theory of evidence for Evidence-Based Policy. In W. Twining, P. Dawid, \& D. Vasilaki (Eds.), Evidence, inference, and enquiry (pp. 291322). Oxford: Oxford University Press.

CDD (Chicago Daily Defender). (1967, May 16). Lawyers mull legality of a new pill. Chicago daily defender (daily edition), p. 17. Chicago, IL, United States.

Chang, H. (2011). Beyond case-studies: History as philosophy. In S. Mauskopf \& T. Schmaltz (Eds.), Integrating History and Philosophy of Science (pp. 109-124). Dordrecht: Springer Netherlands.

Chang, M. C. (1959). Degeneration of ova in the rat and rabbit following oral administration of 1-(p-2-diethylaminoethoxyphenyl)-1-phenyl-2-p-anisylethanol. Endocrinology, 65(2), $339-342$.

Chang, M. C. (1964). Effects of certain antifertility agents on the development of rabbit ova. Fertility and Sterility, 15, 97-106.

Chang, M. C. (1967). Physiological mechanisms responsible for the effectiveness of oral contraception. In R. K. B. Hankinson, R. L. Kleinman, \& P. Eckstein (Eds.), Proceedings of the eighth international conference of the International Planned Parenthood Federation, Santiago, Chile, 9-15 April 1967 (pp. 386-392). London: International Planned Parenthood Federation.

Chang, M. C. (1968). Mammalian sperm, eggs, and control of fertility. Perspectives in Biology and Medicine, 11(3), 376.

Chang, M. C., \& Harper, M. J. K. (1966). Effects of ethinyl estradiol on egg transport and development in the rabbit. Endocrinology, 78(4), 860-872. 
Chang, M. C., \& Yanagimachi, R. (1965). Effect of estrogens and other compounds as oral antifertility agents on the development of rabbit ova and hamster embryos. Fertility and Sterility, 16(3), 281-291.

ChoGlueck, C. (2018). The error is in the gap: Synthesizing accounts for societal values in science. Philosophy of Science, 85 (4), 704-725.

Clarke, B., Gillies, D., Illari, P., Russo, F., \& Williamson, J. (2014). Mechanisms and the evidence hierarchy. Topoi, 33(2), 1-22.

Coleman, M. P. (2013). War on cancer and the influence of the medical-industrial complex. Journal of Cancer Policy, 1(3), e31-e34.

Craver, C., \& Darden, L. (2013). In search of mechanisms: Discoveries across the life sciences. Chicago, IL: University of Chicago Press.

Craver, C., \& Tabery, J. (2017). Mechanisms in science. In E. N. Zalta (Ed.), The Stanford encyclopedia of philosophy. Metaphysics Research Lab, Stanford University. https://plato.stanford.edu/archives/spr2017/entries/science-mechanisms/. Accessed 31 August 2018.

Croxatto, H. B. (2005). Nuestra historia: El Instituto Chileno de Medicina Reproductiva (ICMER). http://www.icmer.org/documentos/historia_icmer/nuestra_historia_hbc_02-052011.pdf. Accessed 31 August 2018.

Croxatto, H. B., Brache, V., Pavez, M., Cochon, L., Forcelledo, M. L., Alvarez, F., et al. (2004). Pituitary-ovarian function following the standard levonorgestrel emergency contraceptive dose or a single 0.75 -mg dose given on the days preceding ovulation. Contraception, 70(6), 442-450. 
Croxatto, H. B., Devoto, L., Durand, M., Ezcurra, E., Larrea, F., Nagle, C., et al. (2001). Mechanism of action of hormonal preparations used for emergency contraception: a review of the literature. Contraception, 63(3), 111-121.

Daniels, K., Jones, J., \& Abma, J. C. (2013). Use of emergency contraception among women aged 15-44, United States, 2006-2010. NCHS data brief, no 112. Hyattsville, MD: National Center for Health Statistics. https://www.cdc.gov/nchs/data/databriefs/db112.pdf. Accessed 31 August 2018.

Daniels, K., Mosher, W. D., \& Jones, J. (2013). Contraceptive methods women have ever used: United States, 1982-2010. National health statistics reports, no 62. Hyattsville, MD: National Center for Health Statistics.

Darden, L. (2006). Reasoning in biological discoveries: Essays on mechanisms, interfield relations, and anomaly resolution. Cambridge: Cambridge University Press.

Davis, D. L. (2007). The secret history of the war on cancer. New York: Basic Books.

Díaz, S., Hardy, E., Alvarado, G., \& Ezcurra, E. (2003a). Acceptability of emergency contraception in Brazil, Chile, and Mexico: 1-Perceptions of emergency oral contraceptives. Cadernos de Saúde Pública, 19(5), 1507-1517.

Díaz, S., Hardy, E., Alvarado, G., \& Ezcurra, E. (2003b). Acceptability of emergency contraception in Brazil, Chile, and Mexico. 2-Facilitating factors versus obstacles. Cadernos de Saúde Pública, 19(6), 1729-1737.

Douglas, H. (2009). Science, policy, and the value-free ideal. Pittsburgh, PA: University of Pittsburgh Press.

Douglas, H. (2014). The moral terrain of science. Erkenntnis, 79(S5), 961-979. doi:10.1007/s10670-013-9538-0 
Dragulinescu, S. (2012). On 'stabilising' medical mechanisms, truth-makers and epistemic causality: a critique to Williamson and Russo's approach. Synthese, 187(2), 785-800.

Dragulinescu, S. (2017). Mechanisms and difference-making. Acta Analytica, 32(1), $29-54$.

Durand, M., del Carmen Cravioto, M., Raymond, E. G., Durán-Sánchez, O., De la Luz CruzHinojosa, M., Castell-Rodríguez, A., et al. (2001). On the mechanisms of action of shortterm levonorgestrel administration in emergency. Contraception, 64(4), 227-234.

Ellertson, C., Trussell, J., Stewart, F. H., \& Winikoff, B. (1998). Should emergency contraceptive pills be available without prescription? Journal of the American Medical Women's Association, 53(5 Suppl 2), 226-229.

Elliott, K. (2011). Is a little pollution good for you? Incorporating societal values in environmental research. New York: Oxford University Press.

FDA (Food and Drug Administration). (2003). Nonprescription Drugs Advisory Committee (NDAC) in joint session with the Advisory Committee for Reproductive Health Drugs (ACRHD). Meeting transcript. No. 202/797-2525). Washington D.C.: U.S. Food and Drug Administration.

FDA (Food and Drug Administration). (2006). Label, insert, and CARE program proposal for Plan B. Drugs@FDA database. http://www.accessdata.fda.gov/drugsatfda_docs/label/2006/021045s011lbl.pdf. Accessed 21 August 2018.

FDA (Food and Drug Administration). (2013). Birth control: Medicines to help you. Case documents for the Supreme Court of the United States. https://www.supremecourt.gov/opinions/URLs_Cited/OT2013/13-354/13-354-2.pdf. Accessed 29 April 2016 
Fehr, C., \& Plaisance, K. S. (2010). Socially relevant philosophy of science: An introduction. Synthese, 177(3), 301-316.

FIGO \& ICEC (International Federation of Gynecology and Obstetrics \& International Consortium for Emergency Contraception). (2011). Mechanism of action: How do levonorgestrel-only emergency contraceptive pills (LNG ECPs) prevent pregnancy? New York, NY: Family Care International. http://www.figo.org/sites/default/files/uploads/MOA_FINAL_2011_ENG.pdf. Accessed 31 August 2018.

Foster, A. M., \& Wynn, L. L. (2012). Emergency contraception: The story of a global reproductive health technology. New York: Palgrave Macmillan.

Fridman, E. P. (2002). Medical primatology: History, biological foundations and applications. (R. D. Nadler, Ed.). London; New York: CRC Press.

Garmendia, F., Kesserü, E., Urdanivia, E., \& Valencia, M. (1976). Luteinizing hormone and progesterone in women under postcoital contraception with D norgestrel. Fertility and Sterility, 27(11), 1250-1255.

Glasier, A., Thong, K. J., Dewar, M., Mackie, M., \& Baird, D. T. (1992). Mifepristone (RU 486) compared with high-dose estrogen and progestogen for emergency postcoital contraception. New England Journal of Medicine, 327(15), 1041-1044.

Glennan, S. (2002). Rethinking mechanistic explanation. Philosophy of Science, 69(S3), S342S353.

Glennan, S. (2016). Mechanisms and mechanical philosophy. In P. Humphreys (Ed.), The Oxford Handbook of Philosophy of Science. Oxford University Press. 
GRADE Working Group. (2004). Grading quality of evidence and strength of recommendations. BMJ, 328(7454), 1490.

Greep, R. O. (1995). Min Chueh Chang, 1908-1991. Biographical Memoir. National Academy of Sciences. http://www.nasonline.org/publications/biographical-memoirs/memoirpdfs/chang-m-c.pdf. Accessed 31 August 2018.

Gross, S. E., Lavi, S., \& Boas, H. (2018). Medicine, technology, and religion reconsidered: The case of brain death definition in Israel. Science, Technology, \& Human Values, https://doi-org.proxyiub.uits.iu.edu/10.1177/0162243918783477

Grou, F., \& Rodrigues, I. (1994). The morning-after pill — How long after? American Journal of Obstetrics and Gynecology, 171(6), 1529-1534.

Guttmacher Institute. (2018). Targeted Regulation of Abortion Providers. Fact sheet. Guttmacher Institute. https://www.guttmacher.org/state-policy/explore/targeted-regulation-abortionproviders. Accessed 31 August 2018.

Guyatt, G., Rennie, D., Meade, M., \& Cook, D. (2015). Users' guides to the medical literature: A manual for evidence-based clinical practice. New York: McGraw-Hill Education Medical.

Hapangama, D., Glasier, A. F., \& Baird, D. T. (2001). The effects of peri-ovulatory administration of levonorgestrel on the menstrual cycle. Contraception, 63(3), 123-129.

HAS (Haute Autorite de Sante). (2015). NORLEVO 1,5 mg, comprimé, renouvellement de l'inscription. Renewal of registration. French National Authority of Health. https://www.has-sante.fr/portail/upload/docs/evamed/CT13654_NORLEVO_PIS_RI_Avis1_CT13654.pdf . Accessed 31 August 2018. 
Hatcher, R. A., \& Conrad, C. C. (1971). Adenocarcinoma of the vagina and stilbestrol as a “morning-after” pill. New England Journal of Medicine, 285(22), 1264-1265.

Holman, B. (2017). Philosophers on drugs. Synthese. https://doi.org/10.1007/s11229-017-1642-2

Holman, B., \& Bruner, J. (2017). Experimentation by industrial selection. Philosophy of Science, 84(5), 1008-1019.

Hoshino, K. (1993). Legal status of brain death in Japan: Why many Japanese do not accept "brain death" as a definition of death. Bioethics, 7(2-3), 234-238.

Howick, J. (2011). The philosophy of evidence-based medicine. West Sussex, UK: WileyBlackwell, BMJ Books.

Hughes, E. C. (1972). Obstetric-gynecologic terminology: With section on neonatology and glossary of congenital anomalies. Philadelphia: Davis.

Hurlbut, J. B. (2017). Experiments in democracy: Human embryo research and the politics of bioethics. New York: Columbia University Press.

Illari, P. (2011). Mechanistic evidence: Disambiguating the Russo-Williamson thesis. International Studies in the Philosophy of Science, 25(2), 139-157.

Illari, P. (2017). Mechanisms in medicine. In M. Solomon, J. R. Simon, \& H. Kincaid (Eds.), The Routledge companion to philosophy of medicine (pp. 48-57). Routledge.

Illari, P., \& Williamson, J. (2012). What is a mechanism? Thinking about mechanisms across the sciences. European Journal for Philosophy of Science, 2(1), 119-135.

Jackson, M. (1967). Recent developments in the biological control of fertility: Report from the medical session. In R. K. B. Hankinson, R. L. Kleinman, \& P. Eckstein (Eds.), Proceedings of the eighth international conference of the International Planned 
Parenthood Federation, Santiago, Chile, 9-15 April 1967 (pp. 484-486). London: International Planned Parenthood Federation.

Jasanoff, S. (1990). The fifth branch: Science advisers as policymakers. Cambridge, MA: Harvard University Press.

Kahlenborn, C., Peck, R., \& Severs, W. B. (2015). Mechanism of action of levonorgestrel emergency contraception. The Linacre Quarterly, 82(1), 18-33.

Kahlenborn, C., Stanford, J. B., \& Larimore, W. L. (2002). Postfertilization effect of hormonal emergency contraception. Annals of Pharmacotherapy, 36(3), 465-470.

Kennedy, A. (2018). Solving antibiotic resistance with the power of evolution. The Prindle Post. https://www.prindlepost.org/2018/06/solving-antibiotic-resistance-with-the-power-ofevolution/. Accessed 31 August 2018.

Kesserü, E., Camacho-Ortega, P., Laudahn, G., \& Schopflin, G. (1975). In vitro action of progestogens on sperm migration in human cervical mucus. Fertility and Sterility, 26(1), $57-61$.

Kesserü, E., Garmendia, F., Westphal, N., \& Parada, J. (1974). The hormonal and peripheral effects of d-norgestrel in postcoital contraception. Contraception, 10(4), 411-424.

Kitcher, P. (2011). Science in a democratic society. Amherst, NY: Prometheus Books.

Kohorn, E. I. (2009). John McLean Morris: A career in surgery, gynecology and reproductive physiology. Connecticut Medicine, 73(4), 223-227.

La Caze, A. (2011). The role of basic science in evidence-based medicine. Biology \& Philosophy, 26(1), 81-98.

Lader, L. (1966, April 10). Three men who made a revolution. New York Times, p. 181. New York, NY. 
Lalitkumar, P. G. L., Lalitkumar, S., Meng, C. X., Stavreus-Evers, A., Hambiliki, F., Bentin-Ley, U., \& Gemzell-Danielsson, K. (2007). Mifepristone, but not levonorgestrel, inhibits human blastocyst attachment to an in vitro endometrial three-dimensional cell culture model. Human Reproduction, 22(11), 3031-3037.

Landgren, B.-M., Aedo, A.-R., Johannisson, E., Kumar, A., \& Yong-en, S. (1989). The effect of levonorgestrel administered in large doses at different stages of the cycle on ovarian function and endometrial morphology. Contraception, 39(3), 275-289.

Langston, N. (2010). Toxic bodies: Hormone disruptors and the legacy of DES. New Haven, CT: Yale University Press.

Larimore, W. L., \& Stanford, J. B. (2000). Postfertilization effects of oral contraceptives and their relationship to informed consent. Archives of Family Medicine, 9(2), 126-133.

Larimore, W. L., Stanford, J. B., \& Kahlenborn, C. (2004). Does pregnancy begin at fertilization? Family Medicine, 36(10), 690-691.

Longino, H. E. (1990). Science as social knowledge. Princeton, NJ: Princeton University Press.

Luker, K. (1984). Abortion and the politics of motherhood. Berkeley: University of California Press.

Lynch, W. A. (1977). Comments on "Medication to prevent pregnancy after rape." Linacre Quarterly, 44(3), 223-228.

Machamer, P., Darden, L., \& Craver, C. F. (2000). Thinking about mechanisms. Philosophy of Science, 67(1), 1-25.

Marchionni, C., \& Reijula, S. (2019). What is mechanistic evidence, and why do we need it for evidence-based policy? Studies in History and Philosophy of Science Part A, 73, 54-63. 
Marions, L., Hultenby, K., Lindell, I., Sun, X., Stla abi, B., \& Danielsson, K. G. (2002).

Emergency contraception with mifepristone and levonorgestrel: mechanism of action. Obstetrics \& Gynecology, 100(1), 65-71.

Marks, L. V. (2001). Sexual chemistry: A history of the contraceptive pill. New Haven, CT: Yale University Press.

Marsh, M. S., \& Ronner, W. (2008). The fertility doctor: John Rock and the reproductive revolution. Baltimore, MD: Johns Hopkins University Press.

McCarthy, D. (1977). Medication to prevent pregnancy after rape. Linacre Quarterly, 44(3), $210-222$.

McCarthy, D. (1978). Pregnancy after rape. Linacre Quarterly, 45(1), 8.

Miller, P. (2015). Good Catholics: The battle over abortion in the Catholic Church. University of California Press.

Moggia, A., Beauquis, A., Ferrari, F., Torrado, M. L., Alonso, J. L., Koremblit, E., \& Mischler, T. (1974). The use of progestogens as postcoital oral contraceptives. The Journal of Reproductive Medicine, 13(2), 58-61.

Morris, J. M., \& Van Wagenen, G. (1966). Compounds interfering with ovum implantation and development: III. The role of estrogens. American Journal of Obstetrics and Gynecology, $96(6), 804-815$.

Morris, J. M., \& Van Wagenen, G. (1973). Interception: The use of postovulatory estrogens to prevent implantation. American Journal of Obstetrics and Gynecology, 115(1), 101-106.

Morris, J. M., Van Wagenen, G., Hurteau, G. D., Johnston, D. W., \& Carlsen, R. A. (1967). Compounds interfering with ovum implantation and development. I. Alkaloids and antimetabolites. Fertility and Sterility, 18(1), 7-17. 
Morris, J. M., Van Wagenen, G., McCann, T., \& Jacob, D. (1967). Compounds interfering with ovum implantation and development. II. Synthetic estrogens and antiestrogens. Fertility and Sterility, 18(1), 18-34.

Müller, A. L., Llados, C. M., \& Croxatto, H. B. (2003). Postcoital treatment with levonorgestrel does not disrupt postfertilization events in the rat. Contraception, 67(5), 415-419.

Naqvi, R. H., \& Warren, J. C. (1971). Interceptives: Drugs interrupting pregnancy after implantation. Steroids, 18(6), 731-739. doi:10.1016/0039-128X(71)90032-8

NCCB (National [United States] Conference of Catholic Bishops). (1971). Ethical and Religious Directives for Catholic Health Facilities. Second edition. Washington, D.C.: United States Catholic Conference Office of Publishing and Promotion.

NCCB (National [United States] Conference of Catholic Bishops). (1995). Ethical and Religious Directives for Catholic Health Care Services. Third edition. Washington, D.C.: United States Catholic Conference Office of Publishing and Promotion.

Nudeshima, J. (1991). Obstacles to brain death and organ transplantation in Japan. The Lancet, $338(8774), 1063-1064$.

Ortiz, M. E., Ortiz, R. E., Fuentes, M. A., Parraguez, V. H., \& Croxatto, H. B. (2004). Postcoital administration of levonorgestrel does not interfere with post- fertilization events in the new- world monkey Cebus apella. Human Reproduction, 19(6), 1352-1356.

Parkes, A. S. (1967). Future trends. In R. K. B. Hankinson, R. L. Kleinman, \& P. Eckstein (Eds.), Proceedings of the eighth international conference of the International Planned Parenthood Federation, Santiago, Chile, 9-15 April 1967 (pp. 501-506). London: International Planned Parenthood Federation. 
Population Council. (2005). Emergency contraception's mode of action clarified. Population Briefs, 11(2), 3.

Prescott, H. M. (2011). The morning after: A history of emergency contraception in the United States. New Brunswick, NJ: Rutgers University Press.

Robinson, M. D. (2018). Financializing epistemic norms in contemporary biomedical innovation. Synthese. https://doi.org/10.1007/s11229-018-1704-0

Rock, J. (1963). The time has come: A Catholic doctor's proposals to end the battle over birth control. New York: Knopf.

Rock, J. (1965). Let's be honest about the Pill! Journal of the American Medical Association, 192(5), 401-402.

Rolin, K. (2017). Scientific community: A moral dimension. Social Epistemology, 31(5), 468483.

Rossiter, M. W. (1982). Women scientists in America: Struggles and strategies to 1940. Baltimore, MD: Johns Hopkins University Press.

Rothman, D. J. (2003). Strangers at the bedside: A history of how law and bioethics transformed medical decision making. 2nd ed. New York: Aldine de Gruyter.

Russo, F. (2012). Public health policy, evidence, and causation: Lessons from the studies on obesity. Medicine, Health Care and Philosophy, 15(2), 141-151.

Russo, F., \& Williamson, J. (2007). Interpreting causality in the health sciences. International Studies in the Philosophy of Science, 21(2), 157-170.

Russo, F., \& Williamson, J. (2011). Epistemic causality and evidence-based medicine. History and Philosophy of the Life Sciences, 33(4), 563-582. 
Russo, F., \& Williamson, J. (2012). EnviroGenomarkers: The interplay between mechanisms and difference making in establishing causal claims. Medicine Studies, 3(4), 249-262.

Schiappacasse, V., \& Díaz, S. (2012). Chile: One step forward, one step back. In A. M. Foster \& L. L. Wynn (Eds.), Emergency contraception: The story of a global reproductive health technology (pp. 107-122). New York: Palgrave Macmillan.

Schickore, J., \& Steinle, F. (2006). Revisiting discovery and justification: Historical and philosophical perspectives on the context distinction. Netherlands: Springer.

Scientific American (1966, June). Retroactive birth control. Scientific American, 214(6), 56.

Shirley, B., Bundren, J. C., \& McKinney, S. (1995). Levonorgestrel as a postcoital contraceptive. Contraception, 52(5), 277-281.

Sjövall, T. (1967). Summary of the conference. In R. K. B. Hankinson, R. L. Kleinman, \& P. Eckstein (Eds.), proceedings of the eighth international conference of the International Planned Parenthood Federation, Santiago, Chile, 9-15 April 1967 (pp. 507-513). London: International Planned Parenthood Federation.

Smugar, S. S., Spina, B. J., \& Merz, J. F. (2000). Informed consent for emergency contraception: variability in hospital care of rape victims. American Journal of Public Health, 90(9), $1372-1376$.

Solomon, M. (2011). Just a paradigm: Evidence-based medicine in epistemological context. European Journal for Philosophy of Science, 1(3), 451-466.

Solomon, M. (2015). Making medical knowledge. Oxford, UK: Oxford University Press.

Spona, J., Matt, K., \& Schneider, W. h. f. (1975). Study on the action of D-norgestrel as a postcoital contraceptive agent. Contraception, 11(1), 31-43. 
Stanford, J. B. (2011). Testimonies: Joseph B. Stanford. Mormon Scholars Testify. http://mormonscholarstestify.org/2691/joseph-b-stanford. Accessed 31 August 2018.

Stanford, J. B., Hager, W. D., \& Crockett, S. A. (2004). The FDA, politics, and Plan B: To the editor. New England Journal of Medicine, 350(23), 2413-2414.

Steele, K. (2012). The scientist qua policy advisor makes value judgments. Philosophy of Science, 79(5), 893-904.

Supreme Court of the United States. (2013). Brief for respondents, on petition for a writ of certiorari to the United States Court of Appeals for the Tenth Circuit, no 13-354. http://sblog.s3.amazonaws.com/wp-content/uploads/2013/10/No-13-354-Brief-forRespondents.pdf. Accessed 31 August 2018.

Supreme Court of the United States. (2014). Syllabus: Burwell v. Hobby Lobby Stores, no 13354 and 13-356. https://www.supremecourt.gov/opinions/13pdf/13-354_olp1.pdf. Accessed 31 August 2018.

Thagard, P. (1999). How scientists explain disease. Princeton, NJ: Princeton University Press. Thagard, P. (2011). Patterns of medical discovery. In F. Gifford (Ed.), Philosophy of medicine (pp. 187-202). Amsterdam: Elsevier North-Holland.

Time. (1966, May 6). The morning-after pill. Time, 87(18), 74.

Tone, A. (2001). Devices and desires: A history of contraceptives in America. New York: Hill and Wang.

Ugocsai, G., Resch, B., Traub, A., \& Sas, M. (1984). Biological, microscopic and scanning electron microscopic investigations of the effects of postinor d-norgestrel in rabbits. Contraception, 30(2), 153-159. 
Watkins, E. S. (1998). On the Pill: A social history of oral contraceptives, 1950-1970. Baltimore, MD: Johns Hopkins University Press.

Weaver, S. (2017). The harms of ignoring the social nature of science. Synthese. https://doi.org/10.1007/s11229-017-1479-8

WHO (World Health Organization). (2017). WHO model list of essential medicines. 20th list. http://www.who.int/medicines/publications/essentialmedicines/20th_EML2017_FINAL_ amendedAug2017.pdf. Accessed 31 August 2018.

Wilks, J. (2000). The impact of the Pill on implantation factors: New research findings. Ethics and Medicine, 16(1), 15-22.

Williams, D. K. (2016). Defenders of the unborn: The Pro-life Movement before Roe v. Wade. New York, NY: Oxford University Press.

Wynn, L. L., \& Trussell, J. (2006). The social life of emergency contraception in the United States: Disciplining pharmaceutical use, disciplining sexuality, and constructing zygotic bodies. Medical Anthropology Quarterly, 20(3), 297-320. 